\title{
Individual Values and Work/Non-Work Conflict in Their Relationship to OCB
}

\author{
Aaron Cohen \& Efrat Liani \\ Department of Public Administration \\ School of Political Science \\ University of Haifa \\ Haifa, 31905, Israel \\ E-mail: acohen@poli.haifa.ac.il
}

Received: Oct. 30, 2017 Accepted: Dec. 10, 2017 Online published: Dec. 12, 2017

doi:10.5296/ijhrs.v8i1.12281 URL: https://doi.org/10.5296/ijhrs.v8i1.12281

\begin{abstract}
This study examines the relationship between (1) individual values, (2) work and non-work variables, and (3) organizational citizenship behavior (OCB) and in-role performance. The study sample consisted of 372 teachers employed in 32 secular Jewish schools (the response rate was 60\%). Data on OCB and in-role performance were provided by the schools' principals. The results showed that three out of the four individual values (self-enhancement, self-transcendence, and conservation) were related to the two forms of OCB, altruistic and organizational, but not to in-role performance. The findings also showed a weak relationship between the non-work variables and the outcome variables, and a modest relationship between the work-domain variables and these outcomes. We concluded by suggesting some directions for such research.
\end{abstract}

Keywords: individual values, non-work domain; commitment in the workplace, organizational citizenship behavior; work-nonwork conflict

\section{Introduction}

Organizational citizenship behavior (OCB) has become one of the more researched outcomes in the field of organizational behavior and industrial psychology (Ehrhart \& Naumann, 2004). The term OCB denotes organizationally beneficial behaviors that can neither be imposed on the basis of formal role obligations nor extracted by a contractual guarantee of compensation; it includes both organizational OCB (OCB-O) (impersonal OCB directed toward the organization in general) and interpersonal $O C B$ (OCB-I) (helping a specific person within the organization) 
(Organ, Podsakoff, \& MacKenzie, 2006). Most research on the determinants of OCB has focused on the work attitudes of subordinates and their relationship with their supervisors, as demonstrated in concepts such as leadership style or commitment. OCB antecedents are usually examined within the theoretical framework of exchange (Carpenter, Berry \& Houston, 2014), which is described as taking place primarily at the individual level, between supervisors and their subordinates (Konovsky \& Pugh, 1994). Despite the impressive amount of studies on OCB, (LePine, Erez, \& Johnson, 2002; Podsakoff, Mackenzie, Paine, \& Bacharach, 2000), only a few studies have considered the effect of individual values and the work/non-work interface on OCB.

A small number of studies have examined individual values in the context of work performance and the work and non-work interface (Cohen, 2009; Carlson \& Kacmar, 2000; Cohen \& Abedallah, 2013; Cohen \& Liani, 2009; Promislo, Deckop, Giacalone \& Jurkiewicz, 2010). Values play a functional role in work-related processes and outcomes, such as job satisfaction, organizational commitment, and work performance (Cohen, 2007; Cohen \& Keren, 2008). They are predictors or moderators of these processes and criteria (Hui, Wong, \& Tjosvold, 2007). Furthermore, they have an important role in establishing the fit between the individual and the organization. There is general agreement in the literature that values do not influence people's activity directly, but rather indirectly, through attitudes and goals (Roe \& Ester, 1999). It is surprising, however, that only a few studies have examined individual values in their relationship to work performance.

Another important issue that is examined here is the relationship between work and family interface and work outcomes. The question of how to strike a balance between work and life, and more specifically between work and family, is attracting increasing attention among academics and policy makers at both the national and international level (Crompton \& Lyonette, 2006). Work-family conflict is a form of inter-role conflict whereby the fulfillment of the role demands emanating from one domain (i.e., work) interferes with fulfilling the role demands in another domain (i.e., home or family) (Kinman \& Jones, 2008). Interest in this issue has grown with the increase in dual-career couples and single-parent households and the concomitant decrease in traditional single-income families (Cousins and Tang, 2004), trends that have resulted in increasing numbers of employees struggling to juggle the competing demands of work and family (Byron, 2005). For example, a person has to choose between participating in a weekend project team meeting and a surprise birthday party for a parent (Greenhaus \& Powell, 2003). The outcomes of multiple role participation may depend not only on the extent of role demands but also on how well competing demands are managed using coping strategies, namely, the strategies that people use to cope with work and family role demands (Jennings \& McDougald, 2007; Ten Brummelhuis \& Bakker,2012; Kirchmeyer, 1993; Cohen, 2009). Commonly investigated coping strategies include: segmentation, compensation, and accommodation. (Greenhaus \& Powell, 2006). Work-family balance issues affect not only employees' well-being, but also their behaviors at work, s such as absenteeism, job performance, and turnover (Eby, Casper, Lockwood, Bordeaux, \& Brinley, 2005). Studies also found that work-family balance is positively related to OCB). For example, Bhargava and Baral (2009) found that family to work enrichment and work to family enrichment were positively related to OCB among Indian managers, and Carlson, 
Kacmar, Grzywacz, Tepper, and Whitten (2013) found that greater work-family balance was associated with higher supervisor-reported altruistic OCB and organizational OCB.

This study examines individual values, organizational commitment, job involvement, work-family conflict, and coping strategies in relation to in-role performance and OCB, drawing data from a sample of Israeli teachers. This study has the potential to make several contributions. First, it applied the theory of human values (Schwartz, 1992), not commonly used at the individual level in management and industrial psychology, particularly in research on work performance. Hardly any studies examined this theory at the individual level and in relationship to OCB and in-role performance. Second, this research also responds to recent criticism that efforts to explain value differences are too narrow and focus almost exclusively on individualism-collectivism (Francesco \& Chen, 2004; Gelfand, Erez, \& Aycan, 2007). Third, this study examines the mutual relationship of values and work and non-work variables with OCB and in role performance. Very few studies examined the relationship of individual values as advanced by Schwartz's human values theory with work outcomes when both work and non-work variables are included in the equation. Such an examination enables us to see whether the effect of individual values holds when important situational variables are included in the equation.

\section{Conceptual Framework and Research Hypotheses}

\subsection{Individual Values and Work Outcomes}

Schwartz's Individual Values Model

Schwartz and Sagiv (1995) defined human values as "...desirable goals, varying in importance, that serve as guiding principles in people's lives. The crucial content aspect that distinguishes these values from one another is the type of motivational goal they express... (pp 93-94)". Schwartz $(1992,1996)$ derived a typology of the different content of values by reasoning that values represent, in the form of conscious goals, three universal requirements of human existence: biological needs, the requisites of coordinated social interaction, and the demands of group functioning. Groups and individuals represent these requirements cognitively as specific values about which they communicate. Values occupy a central position in a person's cognitive system, and for this reason values influence our attitudes, decision-making processes, and in general, all human behaviors.

Schwartz and Sagiv (1995) derived 10 distinct motivational types of values from the three universal requirements (see Figure 1). The 10 values are: self-direction, stimulation, hedonism, security, conformity, tradition, power, achievement, hedonism, universalism and benevolence. Evidence for this theoretical structure has been found in samples from 67 nations (Schwartz, 1992, 2005; Schwartz \& Sagiv, 1995) as well as in recent data from 38 countries (Fontaine, Poortinga, Delbeke, \& Schwartz, 2008). The findings provide substantial support for both the content and structure postulates of the theory and specifically for the claim that 10 motivationally distinct value types are recognized across cultures and used to express value priorities. Research examining the 10 values in samples of the Israeli workforce provided findings that support their usefulness in predicting attitudes and behaviors in the Israeli setting (Cohen, 2009; Abd El Majid \& Cohen, 2015). 


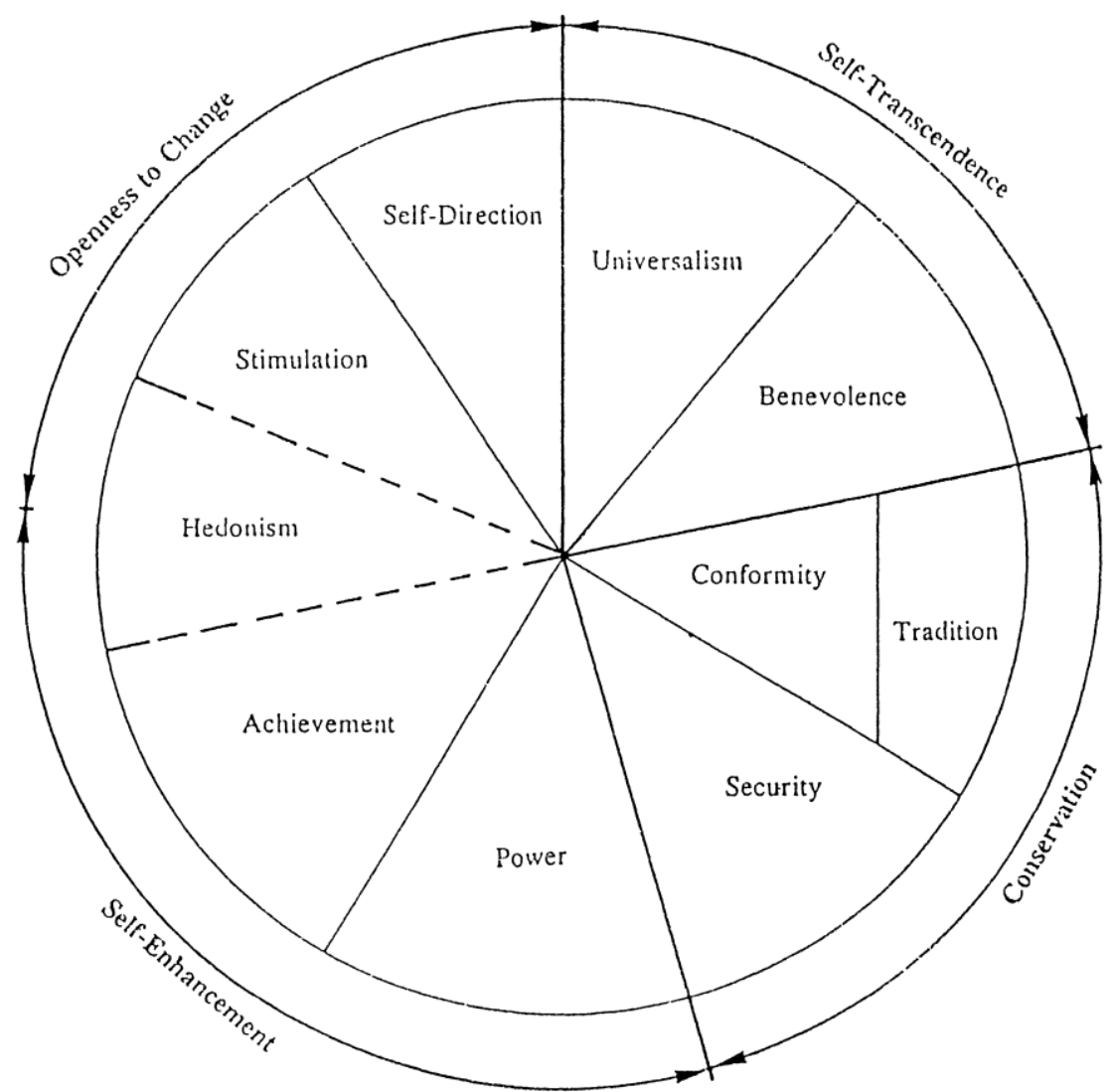

Figure 1. Theoretical model of relations among 10 motivational types of values

The research model is presented in Figure 2. Our first hypothesis argues that values representing openness to change are positively related to performance. These values - namely, self-direction, hedonism, and stimulation - are characterized by independent thinking, creativity, and a willingness to try new things (Schwartz \& Sagiv, 1995), all of which are important preconditions of performance. Lipponen, Bardi, and Haapamäki (2008) studied the extent to which personal values contribute to one type of OCB, making suggestions for improving the organization ("initiative OCB"). The researchers reasoned that initiative OCB is consistent with independence of thought and action (openness to change values), but inconsistent with the motivation to preserve the status-quo (conservation values). They asked employees of day-care centers in Finland to report their personal values. They measured initiative OCB using both self-reports and managers' reports. As hypothesized, both self- and managers' reports revealed that employees who gave high priority to openness to change versus conservation values exhibited more initiative OCB. The effect of these values was stronger among employees who identified strongly with the organization.

Therefore, we could expect that, in the current sample, subjects who showed higher levels of values representing openness to change would score higher in in-role performance and OCB-O than those who held conservation values (tradition, conformity, security).

The latter emphasize order, self-restriction, preservation of the past, and resistance to change (Schwartz, 2010; Sagiv, Schwartz, \& Arieli, 2011) and do not represent important 
requirements of in-role and extra-role performance. Following the above arguments, we advance the first two hypotheses regarding the relationship between individual values and OCB.

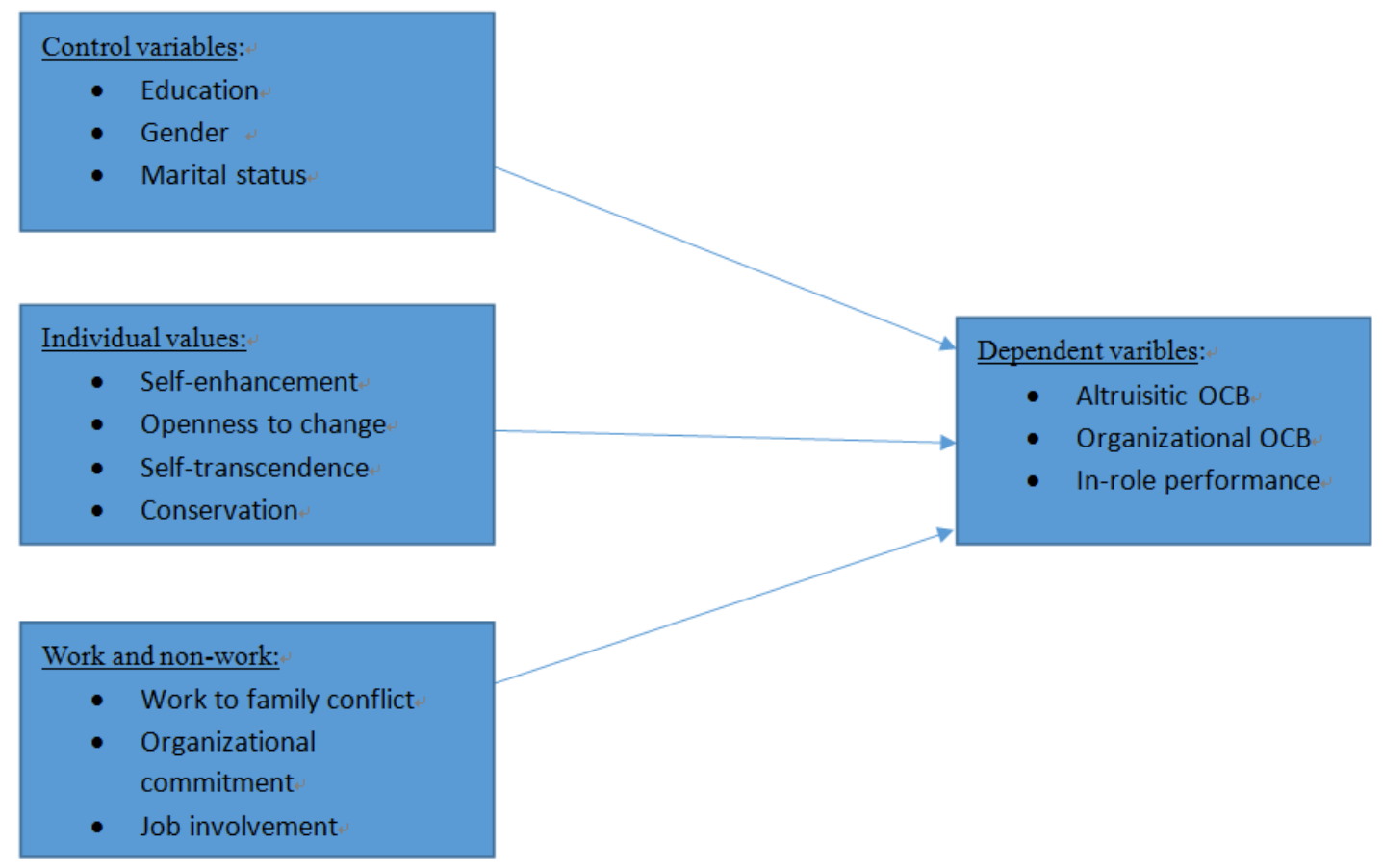

Figure 2. Research model

Hypothesis 1a: There is a positive relationship between values that represent openness to change (self-direction, stimulation, and hedonism) and in-role performance, and OCB-O.

Hypothesis 1b: There is a negative or no relationship between values that represent conservation (tradition, conformity, and security) and in-role performance and OCB-O.

It can be expected that values representing self-transcendence will be related positively to OCB-I and OCB-O. OCB-I involves behaviors aimed at helping the organization as well as other people (whether managers or colleagues) at work and OCB-O involves impersonal actions directed toward helping the organization in general (Podsakoff et al., 2000). This fits with the notion that a person whose values represent self-transcendence is likely to regard the group or collective as being more important than the individual (Schwartz, 1992, 1996), and therefore will be more likely to demonstrate OCB-I and OCB-O in her/his relationships at work. High self-transcendence values emphasize acceptance of others as equals and concern for their welfare (universalism and benevolence) (Schwartz, 2005). Employees who hold such values will be inclined to help other employees when they can, and will perceive such helping relationships as indicative of the quality of their relationship with the organization. Such employees will have high empathy and tolerance, and will do their best to avoid conflict. Therefore, they will demonstrate higher levels of OCB-I and OCB-O. High self-enhancement values (power, achievement, and hedonism) emphasize the pursuit of one's own relative success and dominance over others. According to Schwartz (2010), people who emphasize 
self-enhancement experience more personal anxiety that might deplete the resources needed for prosocial behavior. Such people also share a negative outlook on human nature. This suggests negative relations between self-enhancement values and prosocial behavior. According to Schwartz (2010), self-enhancement values legitimize attending to one's own needs and avoiding involvement with others who are needy. The pursuit of dominance over people and accumulation of resources inherent in power values justifies self-serving behavior even at the expense of others. Therefore, it can be expected that such employees will be less motivated to engage in OCB-O and OCB-I.

Hypothesis 2: Higher levels of values that represent self-transcendence (universalism and benevolence) are positively and strongly associated with OCB-I and with OCB-O. Higher levels of values that represent self-enhancement (achievement and power) are negatively associated with $O C B-O$ and with $O C B-I$.

\subsection{Work Domain Variables as Predictors of OCB and In-Role Performance}

Affective organizational commitment and job involvement

Affective organizational commitment is defined as "an affective or emotional attachment to the organization such that the strongly committed individual identifies with, is involved in, and enjoys membership in the organization" (Allen \& Meyer, 1990, p. 2). Organizational commitment is hypothesized to lead to improved job performance (Meyer, Stanley, Herscovitch, \& Topolnytsky, 2002) and has become recognized as being among the more stable and consistent determinants of OCB, judging from the number of studies examining their relationship (Meyer et al., 2002; Rioux \& Penner, 2001; Bragger, Rodriguez-Srednicki, Kutcher, Indovino, \& Rosner, 2005). Job involvement - that is, the degree to which employees are engaged in and enthusiastic about performing their work (Kanungo, 1982) - is likely to follow a similar logic as commitment.

As presented in the research model (see Figure 2), we expect that both organizational commitment and job involvement will be related to improved job performance and OCB (Meyer et al., 2002). One theoretical explanation for this expected pattern follows the exchange approach. As described by Cohen (2015), social exchanges entail unspecified obligations. Employees who experience positive exchanges with the organization will reciprocate with higher levels of commitment, which will motivate them to contribute to the organization in other ways, whether formally (through better performance) or in more spontaneous, informal ways, i.e., through higher levels of OCB (Meyer et al., 2002). As for job involvement, Diefendorff, Brown, Kamin, and Lord (2002) argued that, given the fact that job involvement is thought to be an important determinant of effort and motivation and other job attitudes have been shown to positively relate to OCB, it is anticipated that those scoring high in job involvement will engage in more OCB. Their findings supported this argument.

Another explanation as to why commitment and involvement should be related to performance outcomes stems from the congruence effect advanced by Sagiv and Schwartz (2000). According to their thesis, people are more motivated, satisfied, and committed when 
their values are congruent with those of the organization or group (Berings et al., 2004). In other words, a good fit between the values and expectations of the organization and those of the employee will be expressed through high levels of commitment and job involvement. Because most organizational cultures strongly emphasize performance, employees whose value system has a better fit with the notion of performance will adjust better to their work environment and will perform better.

Hypothesis 3: Organizational commitment and job involvement are positively related to in-role performance, $O C B-I$ and $O C B-O$.

\subsection{Non-Work Domain Variables as Predictors of OCB and In-Role Performance}

The work-family conflict

Studies have shown that role conflict is the main dilemma of workers (Frone, Russell, \& Cooper, 1991; Frone, Yardley, \& Markel, 1997). Work and family are the most important role domains in the lives of most individuals. However, the expectations of the roles are not always compatible, and frequently create conflicts between the family and work domains. The conflict develops because employees perform more than one task in each domain. Being a spouse and/or a parent and being an employee or a manager requires a great deal of psychic energy, of which human beings have limited amounts. The theory of conformance to social expectations suggests that the family environment of men and women may have a significant impact on their career success. Despite the widely touted "family friendly" focus of the 1990s, recent research has found some evidence of the potentially detrimental career effects of a family (Almer, Cohen \& Single, 2004). Cohen (1999) found that family domain variables were strongly related to voluntary turnover of male and female lawyers. The benefits of engaging in work and family roles may also increase the intrinsic motivation of an individual to go beyond normal role demands at work (Bhargava \& Baral, 2009). According to Carlson et al. (2013), favorable environmental circumstances that are persistent and have sufficient force, elicit a broader and structured effect. Positive emotions are best targeted by creating circumstances, events, or environments that are valued by individuals or have personal meaning and significance. Carlson et al. contended that the work-family balance is such a circumstance, because it is a highly desired but rarely an obtained outcome for a substantial proportion of workers. The basic argument is that the work-family balance generates or sustains a level of positive emotion that stimulates outward seeking behaviors, such as OCB. Accumulated over time, the positive emotions that accompany work-family balance and the resulting pattern of broadened outlooks are likely to build cognitive (e.g., skills) and psychological (e.g., mastery) resources that enable regular engagement in OCB. Therefore, individuals who experience work-family balance will engage in citizenship behaviors (Brager et al., 2005).

In general, employees who experience high levels of work-to-family conflict will act to reduce them. One way of reducing the magnitude of this conflict is to invest less effort at work (Brager et al., 2005). This naturally will lead to lower levels of performance and lower levels of any extra work investments such as OCB. 
Hypothesis 4: Work-to-family conflict is associated negatively with in-role performance and $O C B$.

\subsection{Coping Strategies}

Individuals often rely on their own personal resources and typically fall into preferred behavioral patterns to cope with the work and family conflict (Rotondo \& Kincaid, 2008). Successfully coping with multiple domains involves applying good personal organizational skills and developing an appropriate attitude (Rotondo \& Kincaid, 2008; Cohen, 2009). Kirchmeyer (1993) found that strategies aimed at altering one's own attitudes as opposed to altering those of others, and increasing one's personal efficiency as opposed to decreasing one's activity level or relying on others, appeared to be the most effective techniques for helping employees cope with a multitude of life domains. Those who throughout their lives develop more successful strategies can cope more effectively with daily and conflicting demands from work and family and devote more time to their career.

The type of personal strategy used to cope with the demands and responsibilities of multiple domains appears to affect the experience of interdomain conflict (Hall, 1972; Kirchmeyer, 1993). In general, successful coping with the work/non-work interface has been associated with higher levels of satisfaction in both domains (Hall, 1972; Kinnier, Katz, \& Berry, 1991; Kirchmeyer, 1993). For example, coping strategies such as carefully setting work and non-work priorities, overlapping roles whenever possible, and redefining roles have been associated with low levels of work/non-work conflict, favorable work attitudes, reduced levels of strain, and a low incidence of job withdrawal (Kirchmeyer, 1993; Matsui, Ohsawa, $\&$ Onglatco, 1995). The result is likely to be greater psychological attachment to the organization and higher levels of investment in the organization, namely, higher levels of effort, which will result in higher performance and OCB.

Hypothesis 5: Use of personal coping strategies is associated with high in-role performance and high $O C B$.

\subsection{Control Variables}

While the demographic variables are examined here more as control variables (see Figure 2), we offer justifications for their inclusion based on their expected relationship with the outcome variables. Three demographic variables are examined: marital status, gender, and education. Being married can be an important determinant of performance at work, in that employees who are married must devote more time to family life than those who are not. One would expect that married employees would have less time to devote to extra-role activities, because this time would be invested in their family. Employees who are not married have more time and energy for extra-role activities. Russell and Rush (1987) did find some relationship between marital status and different dimensions of performance and contribution to the organization. In addition, studies show that despite societal changes in traditional gender roles, women still perform more household duties than men do (Karsten, 1994; Ross, 1987). Consistent with this view, we expect that employees who are married and female will have (or will perceive themselves to have) greater responsibilities at home, leading to role 
conflicts and to lower levels of work performance (Kidder \& Parks, 2001).

In several studies, education was examined in its relationship to OCB and in-role performance, in the belief that employees with a higher educational level would perceive their exchange with the organization as more social than calculative. Such employees, who generally occupy the higher ranks in the organization, would more readily acknowledge the importance of the informal support of their co-workers and supervisors. With more financial security, better educated employees can spend more time on social exchange such as OCB. On the other hand, less educated employees would focus on the economic exchange of their workplace. Research findings are not conclusive regarding the relationship between education and OCB: some found a positive relationship (Gregerson, 1993; Smith, Organ \& Near, 1983) and some did not (Organ \& Konovsky, 1989).

Hypothesis 6: Being married, being female, and having a lower level of education is related to lower levels of in-role performance and $O C B$.

\section{Method}

\subsection{Subjects and Procedure}

The population of this study was secular Israeli teachers working in secular Jewish state schools. We focused on this particular group in order to minimize variations that might be caused by including members of other, culturally different, populations, such as Arabs or religious Jews. We distributed questionnaires to 610 teachers in 32 schools (including both elementary and secondary schools) located in Israel; of these, 372 usable questionnaires were returned, a response rate of $60 \%$. The questionnaires included items on individual values, commitment forms, non-work domain variables, and demographic characteristics. The principals of the 32 schools provided data on OCB and in-role performance for those teachers who returned usable questionnaires, in most cases a month or two after the questionnaires were collected. The teachers indicated their national identity numbers on the questionnaires to allow us to match their responses with the principals' evaluations. The questionnaires, which were in Hebrew, took about 15 minutes to complete; no compensation was provided.

The sample can be defined as homogeneous in several respects. Most of the respondents were females $(85.2 \%)$, married $(83.5 \%)$, born in Israel (96\%), and possessing an academic education $(91 \%)$. In other respects, the sample is more heterogeneous, as demonstrated in the relatively high standard deviations of the remaining three variables: age (Mean=39.6; $\mathrm{SD}=10.98$ ), tenure in the school (Mean=9.92; $\mathrm{SD}=8.2$ ), and tenure in the occupation (Mean=14.3; SD=9.40).

\subsection{Scales}

\subsubsection{Individual Values}

The Portrait Values Questionnaire (PVQ) was applied to measure the 10 basic values (Schwartz, 2005; Schwartz, Melech, Lehmann, Burgess, \& Harris, 2001). The PVQ consists of short verbal portraits of 40 different people, gender-matched with the respondent. Each portrait highlights goals and aspirations that point implicitly to the importance of a value. The 
portraits describe each person in terms of what is important to him or her; thus, they capture the person's values without explicitly identifying values as the topic of investigation. The score for the importance of each value is the average rating given to these items (on a 6-point scale), all designated a priori as markers of a value. All the value items have demonstrated near equivalence of meaning across cultures in analyses using multi-dimensional scaling (Schwartz, 2005). Following Schwartz's model, we aggregated the items into the four higher-order value types: conservation (conformity, tradition, and security; 13 items, Cronbach's alpha $=.75$ ), self-transcendence (universalism and benevolence; 10 items; Cronbach's alpha $=.80$ ), self-enhancement (achievement and power; 7 items; Cronbach's alpha $=.77$ ), and openness to change (self-direction, stimulation, and hedonism; 10 items; Cronbach's alpha $=.79$ ).

\subsubsection{Work Domain Variables}

Affective organizational commitment was measured using the eight-item scale developed by Allen and Meyer (1990). It should be noted that the term "the school" or "my school" was used in all organizational commitment items. In addition, two items from the original scale were omitted to increase reliability (Cronbach's alpha $=.68)$. Job involvement (10 items) was measured by the scale developed by Kanungo $(1979,1982)($ Cronbach's alpha $=.77)$.

Non-work domain variables. Work-to-family conflict and family-to-work conflict were measured by two 5-item scales developed by Netemeyer, Boles, and McMurrian (1996). Higher scores mean more conflict. However, the reliability of the family-to-work conflict scores was very low (below .60) and therefore we decided not to include it in the analysis. A high score in work-to-family conflict indicates that demands related to the household and the family have a negative spillover on performing work duties (Cronbach's alpha $=.83$ ). Personal coping was measured using the 16 items of Kirchmeyer's (1993) scale of coping strategies. The items represent common practices utilized to manage multiple domains that were identified in her study of men and women, and involve time management and the reframing of demands (Example items: Concentrate on those activities of nonwork roles that are meaningful to me, and drop the meaningless activities; Arrange with others (such as my kids, other parents, fellow hobbyists) to help with nonwork responsibilities; Increase my efficiency by scheduling and organizing role activities carefully). Three items from this scale were omitted to increase reliability that was below .60 when these items were included. (The deleted items are: Keep roles separate from each other (e.g., keeping work out of family life, choosing community service totally unlike work); Use no conscious strategy to deal with the demands of various roles; Reduce my standards within certain roles (e.g., accepting performance that is "good enough" as opposed to "my best".) We performed exploratory factor analysis (Varimax rotation) on the items of the scale to examine the possibility that this is a multi-dimensional scale. The findings showed one dominant factor (Cronbach's alpha=.68).

\subsubsection{Organizational Citizenship Behavior (OCB) and In-Role Performance}

The Williams and Anderson (1991) scale, a 21-item list, was applied in this study. The principals of the schools were asked to evaluate each of the teachers in the final sample 


\section{Macrothink}

International Journal of Human Resource Studies

ISSN 2162-3058

2018, Vol. 8, No. 1

according to these items. The 21 items represent three dimensions, where 7 items measure in-role performance (Cronbach's alpha=.66), 7 measure OCB-O (impersonal OCB directed toward the organization in general) (Cronbach's alpha=.89), and 7 measure OCB-I (helping a specific person) (Cronbach's alpha=.85).

All the employees' constructs were measured on a 7-point scale ( $1=$ strongly disagree to $7=$ strongly agree). The OCB scale was measured on a scale ranging from 1 (never) to 5 (always).

\subsection{Data Analysis}

As the sample included teachers from 32 different schools, we analyzed the data using Hierarchical Linear Modeling (HLM) (Bryk \& Raudenbush, 1992, pp. 84-86).

\section{Findings}

Table 1 presents the basic statistics of the variables and the inter-correlations among them. The results show acceptable reliabilities of the research variables following DeVellis's (1991) criterion of .60 and above. The correlations among the independent variables were in general not high. In only one case was the correlation above .50 (self-enhancement and openness to change, $\mathrm{r}=.58 ; \mathrm{P} \leq .001)$. These correlations almost preclude the possibility of multicollinearity.

Table 1. Descriptive statistics, reliabilities (in parentheses), and inter-correlations among research variables

\begin{tabular}{|c|c|c|c|c|c|c|c|c|c|c|c|c|c|c|c|c|}
\hline Variables & Mean & SD & 1 & 2 & 3 & 4 & 5 & 6 & 7 & 8 & 9 & 10 & 11 & 12 & 13 & 14 \\
\hline \multicolumn{17}{|l|}{ Control variables } \\
\hline 1. Education & 3.21 & .73 & & & & & & & & & & & & & & \\
\hline 2. Gender ${ }^{1}$ & 0.85 & .36 & .03 & & & & & & & & & & & & & \\
\hline 3. Marital status ${ }^{2}$ & 0.14 & .35 & -.02 & -.02 & & & & & & & & & & & & \\
\hline \multicolumn{17}{|l|}{ Individual values } \\
\hline 4. Self-enhancement & 3.37 & .74 & -.01 & -.06 & -.03 & $(.77)$ & & & & & & & & & & \\
\hline 5. Openness to change & 3.06 & .80 & -.05 & -.08 & -.03 & $.58 * * *$ & $(.79)$ & & & & & & & & & \\
\hline 6. Self-transcendence & 3.93 & .59 & .05 & $-.11^{*}$ & -.01 & $.39 * * *$ & $36 * * *$ & $(.80)$ & & & & & & & & \\
\hline 7. Conservation & 3.22 & .84 & $.18 * *$ & -10 & .09 & $.37 * * *$ & $.15^{* *}$ & $43 * * *$ & $(.75)$ & & & & & & & \\
\hline Work and non-work & & & & & & & & & & & & & & & & \\
\hline $\begin{array}{l}8 \text {. Work to family } \\
\text { conflict }\end{array}$ & 3.04 & 1.24 & $.12 *$ & $-.12^{*}$ & -.01 & .06 & .03 & -.03 & .05 & $(.83)$ & & & & & & \\
\hline $\begin{array}{l}\text { 9. Affective } \\
\text { organizational } \\
\text { commitment }\end{array}$ & 5.77 & .85 & $-.10^{*}$ & .02 & .01 & .08 & .05 & $.18 * *$ & -.08 & $-.21 * *$ & $(.68)$ & & & & & \\
\hline 10 . Job involvement & 4.07 & .81 & -.00 & $.11 *$ & -.01 & $.25 * *$ & $.12 *$ & $.20 * *$ & $-.19 * *$ & .05 & $.30 * * *$ & $(.77)$ & & & & \\
\hline $\begin{array}{l}\text { 11. Coping strategies } \\
\text { Work outcomes }\end{array}$ & 4.66 & .70 & $.15^{* *}$ & .05 & -.01 & $41^{* * *}$ & $.31 * * *$ & $26 * * *$ & $-.18 * *$ & .04 & .08 & $.17 * *$ & $(.68)$ & & & \\
\hline 12. In-role performance & 4.35 & .54 & .02 & $-.12^{*}$ & -.05 & .05 & .03 & .04 & -.00 & -.09 & .05 & -.08 & -.07 & $(.66)$ & & \\
\hline 13. Altruistic OCB & 3.83 & .70 & -.00 & .01 & -.02 & .02 & .02 & .01 & .00 & -.06 & $.13 *$ & -.06 & -.06 & $44 * * *$ & $(.85)$ & \\
\hline $\begin{array}{l}\text { 14. Organizational } \\
\text { OCB }\end{array}$ & 4.18 & .54 & .03 & -.09 & -.10 & -.09 & -.09 & .03 & -.03 & -.07 & .07 & $-.14^{*}$ & -.04 & $.71 * * *$ & $.33 * * *$ & $(.89)$ \\
\hline
\end{tabular}

$*=\mathrm{P} \leq .05 ; * *=\mathrm{P} \leq .01 ; * * *=\mathrm{P} \leq .001$

1 male $=1 ;$ female $=2$

2 not married $=0 ;$ married $=1$.

$\mathrm{N}=364-372$

To establish the discriminant validity of the study scales, confirmatory factor analysis (CFA) 
was performed (Brooke et al., 1988; Mathieu \& Farr, 1991). We first compared the fit of a three-factor model for the three dimensions, OCB (OCB-O and OCB-I) and in-role performance, to the alternative fit of a single, one-factor model. The results for the three-factor model revealed the following fit indices: $\mathrm{X} 2=88.35(\mathrm{DF}=24) ; \mathrm{X} 2 / \mathrm{df}=3.68$; CFI $=.95 ; \mathrm{IFI}=.95 ; \mathrm{NFI}=.94 ;$ and $\mathrm{RMSEA}=.08$. In the second model tested, all items were loaded onto a single factor, producing $\mathrm{X} 2=550.62(\mathrm{DF}=27) ; \mathrm{X} 2 / \mathrm{df}=20.39 ; \mathrm{CFI}=.65 ; \mathrm{IFI}=.66$; $\mathrm{NFI}=.64$; and RMSEA=.23. The findings support the superiority of the three-factor model over the one-factor model. To further examine this contention, a chi-square difference test was conducted. The difference in chi-square between two nested models is used to calculate improvement over a competing model. Significant results for the chi-square difference test indicate that the model with a smaller chi-square has a statistically better fit (Milfont \& Fischer, 2015). The chi-square difference test indicated that the three-factor model fits significantly better than the one-factor model (Chi-square difference=462.27; D.F. $=3 ; \mathrm{P}$ $\leq .001)$.

We also performed CFA for the two commitment scales. We -compared the fit of a two-factor model, including organizational commitment and job involvement, to the alternative fit of a one-factor model. The results for the two-factor model revealed the following fit indices: $\mathrm{X} 2=5.72(\mathrm{DF}=8) ; \mathrm{X} 2 / \mathrm{df}=5.72 ; \mathrm{CFI}=.89 ; \mathrm{IFI}=.89 ; \mathrm{NFI}=.87$; and $\mathrm{RMSEA}=.11$. In the second model, all items were loaded onto a single factor, producing $\mathrm{X} 2=101.29$ (DF=1); X2/df $=11.25 ; \mathrm{CFI}=.73 ; \mathrm{IFI}=.74 ; \mathrm{NFI}=.72$; and $\mathrm{RMSEA}=.16$. The findings support the superiority of the two-factor model over the one-factor model, although the fit indices for the two-factor solution were not very high. Again, a chi-square difference test indicated that the two-factor model fit was significantly better than the one-factor model fit (Chi-square difference $=55.5$; D.F. $=1 ; \mathrm{P} \leq .001)$.

Finally, we performed CFA for all the independent variables in the study. We compared the fit of an eight-factor model that includes the four individual values and the four work and non-work variables to the alternative fit of a one-factor model. The results for the eight-factor model revealed the following fit indices: $\mathrm{X} 2=644.92(\mathrm{DF}=224) ; \mathrm{X} 2 / \mathrm{df}=2.79 ; \mathrm{CFI}=.89$; $\mathrm{IFI}=.90 ; \mathrm{NFI}=.85$; and RMSEA=.07. In the second model, all items were loaded onto a single factor, producing $\mathrm{X} 2=2695.20(\mathrm{DF}=252) ; \mathrm{X} 2 / \mathrm{df}=10.70 ; \mathrm{CFI}=.39 ; \mathrm{IFI}=.39 ; \mathrm{NFI}=.37$; and RMSEA $=.16$. The findings support the superiority of the eight-factor model over the one-factor model. Again, a chi-square difference test indicated that the eight-factor model fit was significantly better than the one-factor model fit (Chi-square difference $=2050.28$; D.F. $=28 ; \mathrm{P} \leq .001)$. This finding shows that the individual values have convergent and discriminant validity with the other independent variables.

These results are consistent with the absence of common method variance. The findings showed that the sample examined here was able to differentiate between the different scales applied in this study.

Table 2 presents the results of the HLM analyses, in which values were regressed on the three outcome variables. Hypothesis 1a expected a positive relationship between values that represent openness to change and in-role performance and OCB. This hypothesis was not 
supported by the data. Openness to change was not related to any of the outcome variables. Hypothesis $1 \mathrm{~b}$ expected a negative or no relationship between values that represent conservation and the outcome variables. This hypothesis was supported by the data. Conservation was negatively related to the two forms of OCB, OCB-I and OCB-O, and had no significant relationship with in-role performance.

Hypothesis 2 expected that employees who had higher levels of values that represent self-transcendence would score higher in OCB-I and OCB-O. This hypothesis was supported by the data. Those who were ranked higher on self-transcendence had higher levels of OCB-I and OCB-O, as expected. Also as expected, higher levels of self-enhancement were associated with lower levels of OCB-I and OCB-O.

Hypothesis 3 expected organizational commitment and job involvement to demonstrate a positive relationship with work outcomes. This hypothesis was also partly supported. The positive relationship between job involvement and OCB-I and in-role performance was expected. However, we did not anticipate the negative relationship found between organizational commitment and OCB-I. Hypothesis 4 expected a negative relationship between work-to-family conflict and the outcome variables; this hypothesis was supported for OCB-I. Hypothesis 5 expected a positive relationship between coping strategies and the outcome variables; this was not supported by the data. All three estimates were not significant.

Table 2. Hierarchical linear modeling analyses (and estimates) of demographics, values, leadership, and commitment on OCB and in-role performance

\begin{tabular}{|c|c|c|c|}
\hline Independent variables & Altruistic OCB & Organizational OCB & In-role performance \\
\hline $\mathrm{N}$ & 330 & 331 & 330 \\
\hline Intercept & $2.35^{* * *}$ & $2.46^{* * *}$ & 1.85 \\
\hline \multicolumn{4}{|l|}{ Demographics } \\
\hline 1. Education & .12 & $.16^{*}$ & .24 \\
\hline 2. Gender $^{1}$ & .03 & -.01 & .07 \\
\hline 3. Marital status ${ }^{2}$ & -.07 & -.07 & .44 \\
\hline \multicolumn{4}{|l|}{ Individual values } \\
\hline 4. Self-enhancement & $-.65 * * *$ & $-.35 * * *$ & -.16 \\
\hline 5. Openness to change & -.01 & .06 & -.02 \\
\hline 6. Self-transcendence & $.19 * * *$ & $.18 * * *$ & -.16 \\
\hline 7. Conservation & $-.33 * * *$ & $-.28 * * *$ & .29 \\
\hline \multicolumn{4}{|l|}{ Work and non-work } \\
\hline 8. Work to family conflict & $-.18 * * *$ & -.07 & .13 \\
\hline $\begin{array}{l}\text { 9. Affective organizational } \\
\text { commitment }\end{array}$ & $-.18 * * *$ & -.04 & .13 \\
\hline 10. Job involvement & $.10^{*}$ & .07 & $.28 * *$ \\
\hline 11. Coping strategies & -.03 & .03 & -.05 \\
\hline Random variance of schools & $.05^{* *}$ & $.09 * *$ & .15 \\
\hline -2loglikelihood & 1363.1 & 721.9 & 1363.1 \\
\hline
\end{tabular}

$*=\mathrm{P} \leq .05 ; * *=\mathrm{P} \leq .01 ; * * *=\mathrm{P} \leq .001$

1 male $=1 ;$ female $=2$

2 not married $=0 ;$ married $=1$. 
As Table 2 shows, the random variance of the group was significant only for in-role performance. That is, for the two dimensions of OCB, the model that takes random variance of the group into account was better than that assuming that all groups on average perform the same. Finally, the control variables showed only one significant relationship: Education was positively related to OCB-I. This provided very partial support for Hypothesis 6.

\section{Discussion}

Not many studies have examined individual values in relation to behavioral outcomes, an unsurprising fact, given that this research direction is quite new (Fischer \& Smith, 2006; Lam, Schaubroeck, \& Aryee, 2002; Abd El Majid \& Cohen, 2015). Some studies have examined the relationship between individual values and commitment (Cohen, 2007; Cohen \& Keren, 2008). However, the main contribution of this study is the simultaneous examination of values, commitment foci, and non-work domain variables in their relationship to in-role and extra-role performance. Such an examination has rarely been performed. The findings show that individual values, commitment, and non-work domain variables are concepts that can increase our understanding of employees' behavior in the workplace, particularly their performance. The findings also suggest a number of interesting and important insights that provide ideas and directions for future research, which are elaborated below.

One of the more interesting findings of the current study is the relationship between self-transcendence values and both dimensions of OCB. This finding strongly suggests that OCB is rooted in personality and that employees who are more willing to help the organization and its members in the workplace are likely to be those who value the group and the collective over the individual. This finding suggests that the use of situational variables as the predominant explanation for employees' performance of OCB may need to be reconsidered, and greater attention paid in future to the role of individual differences (Alexandra Beauregard, 2012). The fact that we found no relationship between any of the values studied here and in-role performance suggests that individual differences might be an important factor in shaping both the magnitude and the type of OCB. In-role performance seems to be related to a set of values that is entirely different from OCB.

In the current study, the pattern of the relationship between individual values and OCB is interesting. For example, while we anticipated that the relationships between individual values and the two dimensions of OCB would differ, the findings showed consistent similar relationships with both OCB dimensions. In other words, it is likely that an individual who is moved to engage in one kind of OCB will also engage in the other. However, the more-situational determinants - and specifically, the work and non-work variables - strongly affected OCB-I, but not OCB-O. It thus appears that while individual values have similar effects on both dimensions of OCB, situational variables have differential effects. It should also be noted in this regard that a differential relationship also exists in the cases of OCB and in-role performance. The latter seems to be affected by a different set of antecedents, not all of which are examined here.

Some findings of this study were unexpected, and perhaps need further elaboration. First, while in accordance with the literature (Diefendorff et al., 2002) we anticipated and found a 
positive relationship between job involvement and OCB and in-role performance, we did not anticipate a negative relationship between organizational commitment and OCB-I. Organizational commitment is considered a strong determinant of OCB, and indeed, affective commitment has been found to be one of its most consistent determinants (Meyer et al., 2002). The negative relationship here, as well as the non-significant relationship with other forms of performance, can perhaps be attributed to the specific setting examined here. Schools in Israel have no control over teachers' salaries, tenure-based promotions, etc. Rather, these matters are determined through negotiations between teachers' unions and the Israeli government. Thus, the school unit might not be perceived as a meaningful focus for commitment by many teachers, perhaps explaining the findings presented here. Future research should explore and replicate this finding in both the Israeli system and other similar systems in other cultures.

Another somewhat unexpected finding is the weak effect of the two non-work variables. The only significant relationship found was the expected negative relationship between work-to-family conflict and OCB-I. Coping strategies had no significant relationship with any of the performance variables. Again, a possible explanation for this finding may lie in the specific setting examined here. In Israel, teachers enjoy many vacations (which coincide with children's vacations) and very flexible work schedules. The profession is thus quite convenient for parents and other individuals with heavy family responsibilities. Perhaps in such a setting, employees experience fewer work-to-family conflicts and therefore have less need to apply coping strategies. More research in a variety of settings is needed to substantiate this explanation.

Finally, this study continues an important research direction, namely, examining the relationship between individual values and employees' attitudes and behaviors at the individual level. Indeed, by examining the impact of values on OCB and in-role behaviors, this study expands this line of research significantly (Ang, Van Dyne \& Begley, 2003; Farh, Hackett, \& Liang, 2007). The study contributes to the literature by examining the relationship between values, work and non-work variables, and performance in a culture very different from that of North American or Europe, thus enhancing our understanding of this relationship. This contribution is important because individual values may have different relationships with outcomes across different cultures, such as the individualist culture of North America or Western Europe vs the collectivist culture of the Arab world (Abd El Majid \& Cohen, 2015; Wasti, Peterson, Breitsohl, Cohen, Jørgensen, Aguiar Rodrigues, ... \& Xu, 2016).

The findings of this study, together with those of others (Cohen, 2007, 2009; Abd El Majid \& Cohen, 2015) support the need for further examination of individual values in the workplace setting. Individual values shape and affect employees' attitudes and behaviors not only across nations and cultures, but also within a given country or a given ethnic group. One important finding of this study is that the effect of individual values holds even when work and non-work variables are included in the equations. The findings showed that self-enhancement, self-transcendence, and conservation values are related to two of the outcome variables, even when their effect is evaluated after the inclusion of work and non-work variables. This finding strongly supports continued examination of individual values as predictors of 
attitudes and behaviors in the workplace. It should be noted that the HLM analysis controlled for any variations that can be attributed to differences among the schools in the levels of commitment and outcomes. Thus, the findings here strongly reflect individual-level variations, not organizational ones.

Several limitations of this research should be noted. First, the target population of this study was Israeli teachers. Therefore, it is difficult to generalizing from the findings here to other cultures or occupations. There is a need for more studies that examine other cultures and occupations before solid conclusions regarding the findings here can be reached. Second, the cross-sectional design limits the possibility of drawing causal conclusions from the relationships found in this study. Despite these limitations, this study draw attention to important findings and its results point on some important directions for future research. More studies can increase our understanding of the effect of individual values and work and non-work attitudes on behavior in the workplace.

\section{References}

Abd, E. M. E., \& Cohen, A. (2015). The role of values and leadership style in developing OCB among Arab teachers in Israel. Leadership \& Organization Development Journal, 36(3), 308-327. https://doi.org/10.1108/LODJ-06-2013-0077

Alexandra, B. T. (2012). Perfectionism, self-efficacy and OCB: the moderating role of gender. Personnel Review, 41, 590-608. https://doi.org/10.1108/00483481211249120

Allen, N. J., \& Meyer, J. P. (1990). The measurement and antecedents of affective, continuance and normative commitment to the organization. Journal of Occupational Psychology, 63, 1-18. https://doi.org/10.1111/j.2044-8325.1990.tb00506.x

Almer, E. D., Cohen, J. R., \& Single, L. E. (2004). Is it the kids or the schedule? The incremental effect of families and flexible scheduling on perceived career success. Journal of Business Ethics, 54, 51-65. https://doi.org/10.1023/B:BUSI.0000043496.47644.38

Ang, S., Van Dyne, L., \& Begley, T. M. (2003). The employment relationships of foreign workers versus local employees: a field study of organizational justice, job satisfaction, performance, and OCB, Journal of Organizational Behavior, 24, 561-583. https://doi.org/10.1002/job.202

Bhargava, S., \& Baral, R. (2009). Antecedents and consequences of work-family enrichment among Indian managers. Psychological Studies, 54, 213-225. https://doi.org/10.1007/s12646-009-0028-z

Bragger, J. D., Rodriguez, S. O., Kutcher, E. J., Indovino, L., \& Rosner, E. (2005). Work-family conflict, work-family culture, and organizational citizenship behavior among teachers. Journal of Business and Psychology, 20(2), 303-324. https://doi.org/10.1007/s10869-005-8266-0

Brooke, P. P., Russell, D. W., \& Price, J. L. (1988). Discriminant validation of measures of job satisfaction, job involvement and organizational commitment. Journal of Applied 
Psychology, 73, 139-145. https://doi.org/10.1037/0021-9010.73.2.139

Bryk, A., \& Raudenbush, S. (1992). Hierarchical Linear Models: Applications and Data Analysis Methods. Newbury Park, Calif.: Sage.

Byron, K. (2005). A meta-analytic review of work-family conflict and its antecedents. Journal of Vocational Behavior, 67, 169-198. https://doi.org/10.1016/j.jvb.2004.08.009

Carlson, D. S., \& Kacmar, K. M. (2000). Work-family conflict in the organization: Do life role values make a difference? Journal of Management, 26, 1031-1054. https://doi.org/10.1177/014920630002600502

Carlson, D. S., Kacmar, K. M., Grzywacz, J. G., Tepper, B., \& Whitten, D. (2013). Work-family balance and supervisor appraised citizenship behavior: The link of positive affect. Journal of Behavioral and Applied Management, 14, 87-106.

Carpenter, N. C., Berry, C. M., \& Houston, L. (2014). A meta - analytic comparison of self reported and other - reported organizational citizenship behavior. Journal of Organizational Behavior, 35, 547-574. https://doi.org/10.1002/job.1909

Cohen, A. (1999). Turnover among professionals: A longitudinal study of American lawyers, Human Resource Management Journal, 38, 61-75. https://doi.org/10.1002/(SICI)1099-050X(199921)38:1<61::AID-HRM6>3.0.CO;2-E

Cohen, A. (2007). One nation, many cultures: A cross-cultural study of the relationship between personal cultural values and commitment in the workplace to in-role performance and organizational citizenship behavior, Cross-Cultural Research, 2007, 41, 271-300. https://doi.org/10.1177/1069397107302090

Cohen, A. (2009). Individual values and the work/family interface: An examination of High-Tech employees in Israel, Journal of Managerial Psychology, 24, 814-832. https://doi.org/10.1108/02683940910996815

Cohen, A. (2015). Fairness in the Workplace: A Global Perspective. New York, Palgrave McMillan. https://doi.org/10.1057/9781137524317

Cohen, A., \& Abedallah, A. (2013). Work and nonwork determinants of organizational commitment among female Arab teachers in Israel, International Journal of Management, 30 , 224-234.

Cohen, A., \& Keren, D. (2008). Organizational commitment and cultural values: Examining their relationship and their mutual effect on in-role performance and organizational citizenship behaviour. Group \& Organization Management, 33, 425-452. https://doi.org/10.1177/1059601108321823

Cohen, A., \& Liani, E. (2009). Work-family conflict among female employees in Israeli hospitals. Personnel Review, 38, 124-141. https://doi.org/10.1108/00483480910931307

Cousins, C. R., \& Tang, N. (2004). Working time and work and family conflict in the Netherlands, Sweden, and the UK. Work, Employment and Society, 18, 531-549. 
https://doi.org/10.1177/0950017004045549

Crompton, R., \& Lyonette, C. (2006). Work-life 'balance' in Europe. Acta Sociologica, 49, 379-393. https://doi.org/10.1177/0001699306071680

DeVellis, R. F. (1991). Scale development: Theory and applications. Newbury Park, CA: Sage.

Diefendorff, J. M., Brown, D. J., Kamin, A. M., \& Lord, R. G. (2002). Examining the roles of job involvement and work centrality in predicting organizational citizenship behaviors and job performance. Journal of Organizational Behavior, 23, 93-108. https://doi.org/10.1002/job.123

Eby, L. T., Casper, W. J., Lockwood, A., Bordeaux, C., \& Brinley, A. (2005). Work and family research in IO/OB: Content analysis and review of the literature (1980-2002). Journal of Vocational Behavior, 66, 124-197. https://doi.org/10.1016/j.jvb.2003.11.003

Ehrhart, M. G., \& Naumann, S. E. (2004). Organizational citizenship behavior in work groups: A group norms approach. Journal of Applied Psychology, 89, 960-974. https://doi.org/10.1037/0021-9010.89.6.960

Farh, J. L., Hackett, R. D., \& Liang, J. (2007). Individual-level cultural values as moderators of perceived organizational support-employee outcomes relationships in China: Comparing the effects of power distance and traditionality, Academy of Management Journal, 50, 715-729. https://doi.org/10.5465/AMJ.2007.25530866

Fischer, R., \& Smith, P. B. (2006). Who cares about justice? The moderating effect of values on the link between organizational justice and work behavior. Applied Psychology: An International Review, 55, 541-562. https://doi.org/10.1111/j.1464-0597.2006.00243.x

Fontaine, J. R. J., Poortinga, Y. H., Delbeke, L., \& Schwartz, S. H. (2008). Structural equivalence of the values domain across cultures: Distinguishing sampling fluctuations from meaningful variation. Journal of Cross Cultural Psychology, 39, 345-365. https://doi.org/10.1177/0022022108318112

Francesco, A. M., \& Chen, Z. X. (2004). Collectivism in Action. Group \& Organization Management, 29, 425-441. https://doi.org/10.1177/1059601103257423

Frone, M. R., Russell, M., \& Cooper, M. L. (1991). Relationship of work and family stressors to psychological distress: The independent moderating influence of social support, mastery, active coping, and self-focused attention. Journal of Social Behavior and Personality, 6, $227-250$.

Frone, M. R., Yardley, J. K., \& Markel, K. S. (1997). Developing and testing an integrative model of the work-family interface. Journal of Vocational Behavior, 50, 145-167. https://doi.org/10.1006/jvbe.1996.1577

Gelfand, M. J., Erez, M., \& Aycan Z. (2007). Cross-cultural organizational behavior. Annual Review of Psychology, 58, 479-514. 
https://doi.org/10.1146/annurev.psych.58.110405.085559

Greenhaus, J. H., \& Powell, G. N. (2003). When work and family collide: Deciding between competing role demands. Organizational Behavior and Human Decision Processes, 90(2), 291-303. https://doi.org/10.1016/S0749-5978(02)00519-8

Greenhaus, J. H., \& Powell, G. N. (2006). When work and family are allies: A theory of work-family enrichment. Academy of management review,31(1), 72-92. https://doi.org/10.5465/AMR.2006.19379625

Gregerson, H. B. (1993) Multiple commitments at work and extra-role behavior during three stages of organizational tenure. Journal of Business Research, 26, 31-47. https://doi.org/10.1016/0148-2963(93)90041-M

Hall, D. T. (1972). A model of coping with role conflict: The role behavior of college educated women. Administrative Science Quarterly, 17, 471-486. https://doi.org/10.2307/2393827

Hui, C., Wong, A., \& Tjosvold, D. (2007). Turnover intention and performance in China: The role of positive affectivity, Chinese values, perceived organizational support and constructive controversy. Journal of Occupational and Organizational Psychology,80(4), 735-751. https://doi.org/10.1348/096317906X171037

Jennings, J. E., \& McDougald, M. S. (2007). Work-family interface experiences and coping strategies: Implications for entrepreneurship research and practice. Academy of Management Review, 32(3), 747-760. https://doi.org/10.5465/AMR.2007.25275510

Kanungo, R. N. (1979). The concept of alienation and involvement revisited. Psychological Bulletin, 86, 119-138. https://doi.org/10.1037/0033-2909.86.1.119

Kanungo, R. N. (1982). Measurement of job and work involvement. Journal of Applied Psychology, 67, 341-349. https://doi.org/10.1037/0021-9010.67.3.341

Karsten, M. F. (1994). Management and Gender: Issues and Attitudes. Westport, CT: Quorum Books.

Kidder, D. L., \& Parks, J. M. (2001). The good soldier: Who is s(he)? Journal of Organizational Behavior, 22(8), 939-959. https://doi.org/10.1002/job.119

Kinman, G., \& Jones, F. (2008). A life beyond work? Job demands, work-life balance, and wellbeing in UK academics. Journal of Human Behavior in the Social Environment, 17, 41-60. https://doi.org/10.1080/10911350802165478

Kinnier, R. T., Katz, E. C., \& Berry, M. A. (1991). Successful resolutions to the career-versus-family conflict. Journal of Counseling and Development, 38, 107-123. https://doi.org/10.1002/j.1556-6676.1991.tb01541.x

Kirchmeyer, C. (1993). Nonwork-to-work spillover: A more balanced view of the experiences and coping of professional women and men. Sex Roles, 28: 531-552. https://doi.org/10.1007/BF00289679 


\section{Mll Macrothink}

International Journal of Human Resource Studies ISSN 2162-3058 2018, Vol. 8, No. 1

Lam, S. K. S., Schaubroeck, J., \& Aryee, S. (2002). Relationship between organizational justice and employee work outcomes: A cross-national study. Journal of Organizational Behavior, 23, 1-18. https://doi.org/10.1002/job.131

LePine, J. A., Erez, A., \& Johnson, D. E. (2002). The nature and dimensionality of organizational citizenship behavior: A critical review and meta-analysis. Journal of Applied Psychology, 87, 52-75. https://doi.org/10.1037/0021-9010.87.1.52

Lipponen, J., Bardi, A., \& Haapamäki, J. (2008). The interaction between values and organizational identification in predicting suggestion - making at work. Journal of Occupational and Organizational Psychology, 81, 241-248. https://doi.org/10.1348/096317907X216658

Mathieu, J. E., \& Farr, J. L. (1991). Further evidence of the discriminant validity of measures of organizational commitment, job involvement, and job satisfaction. Journal of Applied Psychology, 76, 127-133. https://doi.org/10.1037/0021-9010.76.1.127

Matsui, T., Ohsawa, T., \& Onglatco, M. (1995). Work-family conflict and the stress-buffering effects of husband support and coping behavior among Japanese women. Journal of Vocational Behavior, 47, 178-192. https://doi.org/10.1006/jvbe.1995.1034

Meyer, P. J., Stanley, D. J., Herscovitch, L., \& Topolnytsky, L. (2002). Affective, continuance, and normative commitment to the organization: A meta-analysis of antecedents, correlates, and consequences. Journal of Vocational Behavior, 61, 20-52. https://doi.org/10.1006/jvbe.2001.1842

Meyer, J. P. (2009). Commitment in a Changing World of Work. In Commitment in Organizations: Accumulated Wisdom and New Directions, Edited by Klein, H., Becker, T. E., \& Meyer, J. P. 37-68. New York: Routledge.

Milfont, T. L., \& Fischer, R. (2015). Testing measurement invariance across groups: Applications in cross-cultural research. International Journal of psychological research, 3(1), 111-130. https://doi.org/10.21500/20112084.857

Netemeyer, R. G., Boles, J. S., \& McMurrian, R. (1996). Development and validation of work family conflict and family work conflict scales. Journal of Applied Psychology, 81, 400-410. https://doi.org/10.1037/0021-9010.81.4.400

Organ, D. W. (1988). O.C.B.: The good soldier syndrome. Lexington, MA: Lexington Books.

Organ, D. W., \& Konovsky, M. (1989) Cognitive vs. affective determinants of organizational citizenship behavior. Journal of Applied Psychology, 74, 157-64. https://doi.org/10.1037/0021-9010.74.1.157

Organ, D. W., \& Ryan, K. (1995). A meta-analytic review of attitudinal and dispositional predictors of organizational citizenship behavior. Personnel Psychology, 48, 775-802. https://doi.org/10.1111/j.1744-6570.1995.tb01781.x

Organ, D. W., Podsakoff, P. M., \& MacKenzie S. P. (2006). Organizational Citizenship 
Behavior: Its Nature, Antecedents, and Consequences. London: Sage Publications.

Podsakoff, P. M., Mackenzie, S. B, Paine, J. B., \& Bacharach, G. D. (2000). Organizational citizenship behaviors: A critical review of the theoretical and empirical literature and suggestions for future research. Journal of Management, 26, 513-563. https://doi.org/10.1177/014920630002600307

Promislo, M., Deckop, J., Giacalone, R. A., \& Jurkiewicz, C. L. (2010). Valuing money more than people: The effects of materialism on work-family conflict. Journal of Occupational and Organizational Psychology, 83, 935-953. https://doi.org/10.1348/096317909X480167

Rioux, S. M., \& Penner, L. A. (2001). The causes of organizational citizenship behavior: a motivational analysis. Journal of applied Psychology,86(6), 1306-1314. https://doi.org/10.1037/0021-9010.86.6.1306

Roe, R. A., \& Ester, P. (1999). Values and work: Empirical findings and theoretical perspective. Applied Psychology: An International Review, 48, 1-21. https://doi.org/10.1111/j.1464-0597.1999.tb00046.x

Ross, C. E. (1987). The division of labor at home. Social Forces, 65, 816-833. https://doi.org/10.1093/sf/65.3.816

Rotondo, D. M., \& Kincaid, J. F. (2008). Conflict, facilitation, and individual coping styles across the work and family domains. Journal of Managerial Psychology, 23, 484-506. https://doi.org/10.1108/02683940810884504

Russell, J. E., \& Rush, M. C. (1987). The effects of sex and marital/parental status on performance evaluations and attributions. Sex Roles, 17, 221-36. https://doi.org/10.1007/BF00287627

Sagiv, L., \& Schwartz, S. H. (2000). Value priority and subjective well-being: Direct relations and congruity effects. European Journal of Social Psychology, 30, 177-198. https://doi.org/10.1002/(SICI)1099-0992(200003/04)30:2<177::AID-EJSP982>3.0.CO;2-Z

Sagiv, L., Schwartz, S. H., \& Arieli, S. (2011). Personal values, national culture and organizations: Insights applying the Schwartz value framework. In Ashkanasy, N. N., Wilderom, C., \& Peterson, M. F. (Eds.) The Handbook of Organizational Culture and Climate. Second Edition. Newbury Park, CA: Sage, 515-537. https://doi.org/10.4135/9781483307961.n29

Schwartz, S. H. (1992). Universals in the content and structure of values: Theory and empirical tests in 20 countries. In M. Zanna (Ed.), Advances in Experimental Social Psychology, 25, 1-65. New York: Academic Press.

Schwartz, S. H. (1996). Value priorities and behavior: Applying a theory of integrated value systems. In Seligman, C., Olsen, J. M., \& Zanna, M. P. (Eds.), Values: The Ontario Symposium, 8, 1-25. Hillsdale, NJ: Lawrence Erlbaum Associates Inc.

Schwartz, S. H. (2005). Robustness and fruitfulness of a theory on universals in individual 
human values. In A. Tamayo \& J. B. Porto (Eds.), Idem, 56-95.

Schwartz, S. H. (2010). Basic values: How they motivate and inhibit prosocial behavior. Prosocial Motives, Emotions, and Behavior: The Better Angels of Our Nature, 14, 221-41. https://doi.org/10.1037/12061-012

Schwartz, S. H., \& Sagiv, L. (1995). Identifying culture specifics in the content and structure of values. Journal of Cross Cultural Psychology, 26, 92-116. https://doi.org/10.1177/0022022195261007

Schwartz, S. H., Melech, G., Lehmann, A., Burgess, S., \& Harris, M. (2001). Extending the cross-cultural validity of the theory of basic human values with a different method of measurement. Journal of Cross-Cultural Psychology, 32, 519-542. https://doi.org/10.1177/0022022101032005001

Smith, C. A., Organ, D. W., \& Near, J. P. (1983). Organizational citizenship behavior: Its nature and antecedents. Journal of Applied Psychology, 68, 653-63. https://doi.org/10.1037/0021-9010.68.4.653

Ten, B. L. L., \& Bakker, A. B. (2012). A resource perspective on the work-home interface: The work-home resources model. American Psychologist, 67, 545-556. https://doi.org/10.1037/a0027974

Wasti, S. A., Peterson, M. F., Breitsohl, H., Cohen, A., Jørgensen, F., Aguiar, R. A. C., ... \& $\mathrm{Xu}, \mathrm{X}$. (2016). Location, location, location: Contextualizing workplace commitment. Journal of Organizational Behavior, 37, 613-632. https://doi.org/10.1002/job.2094

Williams, L. J., \& Anderson, S. E. (1991). Job satisfaction and organizational commitment as predictors of organizational citizenship and in-role behaviors. Journal of Management, 17, 601-617. https://doi.org/10.1177/014920639101700305

\section{Copyright Disclaimer}

Copyright for this article is retained by the author(s), with first publication rights granted to the journal.

This is an open-access article distributed under the terms and conditions of the Creative Commons Attribution license (http://creativecommons.org/licenses/by/4.0/). 